\title{
A canção brasileira nos livros didáticos de português como língua adicional
}

\author{
José Peixoto Coelho de Souza \\ University of Manchester \\ jose.coelhodesouza@manchester.ac.uk
}

\begin{abstract}
Resumo
Este artigo tem como objetivo apresentar um panorama sobre o lugar e o papel da canção em livros didáticos de português como língua adicional produzidos no Brasil a fim de compreender de que modo esse gênero discursivo é abordado e com quais objetivos pedagógicos. Com base em Caretta (2007; 2011) e Coelho de Souza (2010), entendemos a canção como um gênero oral, secundário e sincrético, que requer competências específicas para a construção do(s) seu(s) sentido(s) (COSTA, 2002; COELHO DE SOUZA, 2015). Para isso, analisamos 16 livros-texto de 12 séries publicadas entre 1991 e 2010 buscando verificar se há ocorrências de canções nas obras analisadas e se há tarefas para abordá-las. Os resultados da análise evidenciam, por um lado, uma ampla representatividade de canções nos livros didáticos selecionados, visto que $75 \%$ das obras incluem textos desse gênero. Entretanto, as tarefas referentes ao seu estudo, quando existentes, quase sempre tem como objetivo a leitura e a compreensão oral da letra da canção desvinculada de seus usos sociais e de elementos da música, sua outra linguagem constitutiva, para a construção de sentidos, o que nos leva à conclusão de que a canção é vista como um gênero apenas verbal, ou seja, como letra de música.
\end{abstract}

Palavras-chave: Canção como gênero discursivo - Livros didáticos Português como língua adicional

\begin{abstract}
This paper aims to present an overview of the place and role of songs in Portuguese as an Additional Language textbooks published in Brazil in order to analyse how texts of this genre are studied in these books and the pedagogical objectives underlying their study. Based on Caretta $(2007 ; 2011)$ and Coelho de Souza (2010), songs are seen here as an oral, secondary, and syncretic speech genre, which require a set of particular competences for
\end{abstract}


A canção brasileira nos livros didáticos de português...

meaning-making (COSTA, 2002; COELHO DE SOUZA, 2015). For that, 16 textbooks belonging to 12 series published between 1991 and 2010 are analysed as a way to verify if songs are included in these books and whether there are activities to guide their study or not. The results show that there is a wide presence of songs in these textbooks as $75 \%$ of the books include texts of this genre. However, the activities present in these books tend to focus on reading and listening to the lyrics only with no reference to either the music or its social uses. These findings seem to lead to the conclusion that songs are not seen as a multimodal genre in the textbooks analysed but just as song lyrics.

Keywords: Song as a speech genre - textbooks - Portuguese as an additional language

\section{Introdução}

O português brasileiro tem alcançado destaque cada vez maior no mundo globalizado do início do século XXI devido, entre outras razões, ao fato de o Brasil estar entre as cinco principais economias emergentes, junto com a Rússia, Índia, China e África do Sul (BRICS). A crescente procura pelo estudo de Português como Língua Adicional (doravante PLA) pode ser ilustrada pelo aumento no número de inscritos no Celpe-Bras, o exame de proficiência de português brasileiro, que passou de 127 candidatos na sua primeira aplicação em 1998 para 6.861 candidatos em 2010 (CARVALHO, 2012). Para suprir a demanda pelo ensino de português, a área de PLA vem investindo, desde o início da década de 1990, em iniciativas como a fundação de uma sociedade para profissionais desse campo de estudos (a SIPLE ${ }^{1}$ ), a realização de congressos e seminários em nível nacional e internacional (como o CONSIPLE $^{2}$ e o SINEPLA $^{3}$ ), o desenvolvimento e publicação de materiais didáticos e a criação de cursos e disciplinas com o objetivo de formar professores para atuar nessa área (TROUCHE; JÚDICE, 2005).

No que concerne à publicação de materiais didáticos de PLA no Brasil, pode-se afirmar que a consolidação do mercado editorial de

\footnotetext{
${ }^{1}$ Sociedade Internacional de Português Língua Estrangeira

${ }^{2}$ Congresso Internacional da SIPLE.

${ }^{3}$ Simpósio Internacional de Ensino de Português como Língua Adicional.

Horizontes de Linguística Aplicada, ano 16, n. 1, 2017
} 
livros didáticos (doravante LDs) é ainda recente. Apesar de a primeira obra sobre o tema ter sido publicada nos anos $1940^{4}$ (JÚDICE; ALMEIDA, 2006), a produção editorial na área foi bastante incipiente nas décadas seguintes. Foi somente a partir de 1990 que a produção nacional de LDs expandiu-se e, por conseguinte, ampliou-se a variedade de obras e de públicos-alvo a elas direcionado, tanto em relação ao nível de conhecimento do idioma quanto à faixa etária dos alunos (DINIZ, 2008). Ademais, como aponta o autor (DINIZ, 2008, p. 74), é a partir dessa época que "os LDs passam, cada vez mais, a ser acompanhados por outros materiais, como livro do aluno, livro do professor, livro de exercícios, fitas cassetes/CDs, glossários etc.”, como forma de constituírem-se em materiais didáticos mais abrangentes e atrativos para os alunos.

Partindo do pressuposto de que os LDs "significam - através do seu conteúdo $e$ forma - construções específicas da realidade e maneiras específicas de selecionar e organizar o vasto universo do conhecimento possível"5 (APPLE; CHRISTIAN-SMITH, 1991, p. 3, grifo dos autores), este artigo $^{6}$ tem como objetivo apresentar um panorama sobre o lugar e o papel da canção em LDs de PLA produzidos no país a fim de compreender de que modo esse textos desse gênero discursivo são abordados e com quais objetivos pedagógicos. A análise a ser aqui apresentada, de cunho tanto quantitativo e qualitativo, busca responder a duas perguntas norteadoras:

1. Há a ocorrência de letras de canções nos LDs de PLA? Em caso afirmativo, há tarefas para abordá-las? Com que objetivo(s)?

2. Qual é a concepção de canção subjacente aos LDs?

Para tanto, foram analisados os livros-texto de 12 séries (16 volumes) publicadas no Brasil entre 1991 e 2010, abrangendo as

\footnotetext{
${ }^{4}$ A língua portuguesa para estrangeiros, de Töpker.

${ }^{5}$ They signify - through their content and form-particular constructions of reality, particular ways of selecting and organizing that vast universe of possible knowledge. Nossa tradução.
}

${ }^{6}$ Este artigo é um recorte da minha tese de doutorado intitulada Canção: letra e música no ensino de Português como Língua Adicional: uma proposta de letramento literomusical (COELHO DE SOUZA, 2014).

Horizontes de Linguística Aplicada, ano 16, n. 1, 2017 
A canção brasileira nos livros didáticos de português...

seguintes séries: Aprendendo Português do Brasil (LAROCA; BARA; CUNHA, 2003), Avenida Brasil: curso básico de português para estrangeiros - Volumes 1 e 2 (LIMA et al, 1991; 1995), Bem Vindo! A língua portuguesa no Mundo da Comunicação (PONCE et al, 2009), Diálogo Brasil: Curso Intensivo de Português para Estrangeiros (LIMA; IUNES; LEITE, 2003), Estação Brasil: Português para Estrangeiros (BIZON; FONTÃO, 2005), Fala Brasil (FONTÃO; COUDRY, 1995), Falar... Ler... escrever... Português: um Curso para Estrangeiros (LIMA; IUNES, 1999), Muito Prazer (FERNANDES; FERREIRA; RAMOS, 2008), Novo Avenida Brasil - Volumes 1, 2 e 3 (LIMA et al, 2008, 2009, 2010), Português Via Brasil - Um Curso Avançado para Estrangeiros (LIMA; IUNES, 2005), Terra Brasil: Curso de Língua e Cultura (DELL' ISOLA; ALMEIDA, 2008) e Tudo Bem? Português para a nova geração - Volumes 1 e 2 (PONCE; BURIM; FIORISSI, 2000, 2010). $\quad$ A seleção do corpus procurou contemplar obras mais recentes publicadas no Brasil (entre 1991 e 2010), visto ser esse o período de consolidação do mercado editorial de LDs de PLA no Brasil (DINIZ, 2008), enquanto a escolha do livrotexto como objeto de análise se deu por geralmente apresentar uma maior variedade de tarefas e gêneros discursivos do que o livro de exercícios.

Antes de apresentar os dados e a análise dos dados, faremos a seguir uma breve exposição sobre a canção brasileira e seu papel na cultura nacional, e sobre o conceito de canção como gênero discursivo.

\section{A canção brasileira como gênero discursivo}

A canção popular brasileira é um dos nossos produtos culturais mais conhecidos e reconhecidos internacionalmente. Desde a década de $1960^{7}$, artistas da bossa nova e da MPB tais como Tom Jobim, João Gilberto, Caetano Veloso, Chico Buarque, Gilberto Gil e Elis Regina,

${ }^{7} \mathrm{Na}$ verdade, embora a música popular brasileira já transitasse por outros países e continentes, como durante a turnê pela Europa do grupo Os Oito Batutas, liderado por Pixinguinha, e o sucesso de Carmen Miranda na América Latina e nos Estados Unidos durante os anos 1940, isso se dava de forma assistemática até o momento.

Horizontes de Linguística Aplicada, ano 16, n. 1, 2017

106 
entre diversos outros, podem ser considerados mensageiros de elementos da cultura brasileira, materializando-os em versos de cunho poético associados a melodias e harmonias sofisticadas e a ritmos cheios de síncopes e contratempos. Mais recentemente, canções representantes de outros gêneros musicais produzidos no país, como o axé de Ivete Sangalo e de Cláudia Leitte, o sertanejo universitário de Michel Teló, Luan Santana e Gusttavo Lima, o funk carioca com uma levada pop de Naldo Benny e de Anitta, têm rodado o mundo e tocado em bares, discotecas e rádios dentro e fora do país.

No Brasil, a canção popular ocupa um lugar bastante distinto na cultura devido aos diversos papeis que exerce na nossa sociedade, uma vez que "é arte, diversão, fruição, produto de mercado e, por tudo isso, uma referência cultural bastante presente no dia a dia" (HERMETO, 2012, p. 12). Nas suas letras, podemos encontrar histórias, crônicas, relatos, diálogos, ou seja, representações das múltiplas realidades de um país-continente permeado por diferentes culturas e povos que se veem retratados nos sambas, nos carimbós, nas músicas sertanejas, nos forrós e nas milongas, que compõem uma parte do amplo mosaico dos gêneros musicais brasileiros. Nas suas músicas, as batidas e timbres produzidos a partir de instrumentos acústicos, elétricos, eletroacústicos e eletrônicos formam uma amálgama sonora que nos remete a diferentes regiões do Brasil, permitindo ao ouvinte viajar pelo país sem sair do lugar.

Ao ouvirmos uma canção, entramos em contato com um enunciado sincrético formado por duas linguagens (a verbal e a musical) em constante relação dialógica, o que significa que letra e música podem reforçar, atenuar ou subverter o(s) sentido(s) uma da outra. Assim, na ótica dos gêneros do discurso, entendemos canção como um gênero oral, secundário e sincrético (CARETTA, 2007, 2011; COELHO DE SOUZA, 2010), que pressupõe o uso de habilidades específicas para a construção do(s) sentido(s) devido às possíveis integrações entre as linguagens verbal e musical (COSTA, 2002; COELHO DE SOUZA, 2015). Em outras palavras, uma canção só existe em sua materialidade sonora, sua letra pode incorporar e reelaborar elementos de outros gêneros discursivos (como as cartas, os contos e os diálogos) e a construção dos seus sentidos se dá a partir do sincretismo das duas linguagens, uma vez que "o diálogo- 
A canção brasileira nos livros didáticos de português...

decodificação-recepção dos ouvintes não se dá só pela letra ou só pela música, mas no encontro, tenso e harmônico a um só tempo, dos dois parâmetros básicos e de todos os elementos que formam a canção" (NAPOLITANO, 2005, p. 81). Além disso, entendemos que os sentidos de uma canção também decorrem dos seus diferentes usos e funções sociais e da compreensão da interlocução por ela projetada, uma vez que aspectos como quem a compõe, para quem, por quê, onde e quando deixam marcas discursivas tanto na letra quanto na música.

Entretanto, as práticas pedagógicas tradicionalmente relacionadas ao uso de canção no ensino de línguas enfocam essencialmente o estudo da letra desvinculada da linguagem musical, sendo esta ignorada para a atribuição de sentidos. Assim, acaba-se por realizar uma cisão entre suas duas linguagens constitutivas, o que pode acabar por afetar sua compreensão e fruição. Sobre essa questão, Napolitano (2005) afirma que

Este recorte, por mais justificado que seja, traz em si alguns problemas: além de reduzir o sentido global da canção, desconsidera aspectos estruturais fundamentais da composição deste sentido: como o arranjo, a melodia, o ritmo e o gênero. Muitas vezes o impacto e a importância social da canção estão na forma como ela articula a mensagem verbal explícita à estrutura poético-musical como um todo. (NAPOLITANO, 2005, p. 96).

Pelas razões acima mencionadas, acreditamos que se torna necessário compreender melhor o papel e o lugar da canção nos LDs de PLA e a concepção de canção a eles subjacente.

\section{A canção nos livros didáticos de PLA}

A análise das 16 obras apresentadas anteriormente demonstra que apenas quatro não incluem letras de canções entre os textos apresentados. Ou seja, grande parte (75\%) dos LDs investigados 
propõem o estudo de canções brasileiras ${ }^{8}$. Nessas 12 coleções, foram encontradas 62 ocorrências. Como se pode ver na tabela abaixo, as quatro séries que não abordam canções são Diálogo Brasil, Estação Brasil, Muito Prazer e Português Via Brasil. Além disso, verifica-se também que, apesar de a série Novo Avenida Brasil ser uma reelaboração da coleção Avenida Brasil, nos três volumes daquela houve a redução para cinco canções.

Tabela 1 -Número de canções presentes nas coleções analisadas

\begin{tabular}{lc}
\hline Coleção & Número de canções \\
\hline Aprendendo Português do Brasil (2003) (APB) & 6 \\
Avenida Brasil 1 (1991) (AV1) & 2 \\
Avenida Brasil 2 (2005) (AV2) & 7 \\
Bem-Vindo! (2009) (BV) & 3 \\
Diálogo Brasil (2003) (DB) & 0 \\
Estação Brasil (2005) (EB) & 0 \\
Fala Brasil (2004) (FB) & 11 \\
Falar... Ler... Escrever... Português (1999) (FLE) & 6 \\
Muito Prazer (2008) (MP) & 0 \\
Novo Avenida Brasil 1 (2008) (NAV1) & 1 \\
Novo Avenida Brasil 2 (2009) (NAV2) & 1 \\
Novo Avenida Brasil 3 (2010) (NAV3) & 3 \\
Português Via Brasil (2005) (PVB) & 0 \\
Terra Brasil (2008) (TB) & 12 \\
Tudo Bem 1 (2000) (TD1) & 6 \\
Tudo Bem 2 (2010) (TD2) & 4 \\
Total de coleções que incluem canções: 12 & Total de canções: 62 \\
\hline Fonte: Coeth de Souza (2014, p. 23)
\end{tabular}

Fonte: Coelho de Souza (2014, p. 23)

No que se refere à abordagem da canção nos LDs pesquisados, como podemos constatar na Tabela 2, das 62 canções encontradas, apenas $34(54,84 \%)$ incluem tarefas para sua leitura e/ou audição. Em outras palavras, pouco mais da metade das canções encontradas são de fato abordadas, enquanto não é dado nenhum tratamento pedagógico à outra metade. Do mesmo modo, pode-se verificar que, embora as obras

\footnotetext{
${ }^{8}$ Houve a ocorrência de apenas uma canção que não foi produzida no país: Coimbra, um fado português.
} 
A canção brasileira nos livros didáticos de português...

Fala Brasil e Terra Brasil sejam as que incluem o maior número de canções - com 11 ocorrências e 12 ocorrências, respectivamente apenas uma canção em cada uma das duas obras é acompanhada por tarefas.

Tabela 2 - Número de canções com tarefas por coleção

\begin{tabular}{lcc}
\hline Coleções & $\begin{array}{c}\text { Canções } \\
\text { presentes }\end{array}$ & $\begin{array}{c}\text { Canções } \\
\text { com tarefas }\end{array}$ \\
\hline Aprendendo Português Brasileiro & 6 & 5 \\
Avenida Brasil 1 & 2 & 2 \\
Avenida Brasil 2 & 7 & 7 \\
Bem-Vindo! & 3 & 1 \\
Fala Brasil & 11 & 1 \\
Falar... Ler... Escrever... & 6 & 5 \\
Novo Avenida Brasil 1 & 1 & 1 \\
Novo Avenida Brasil 2 & 1 & 1 \\
Novo Avenida Brasil 3 & 3 & 3 \\
Terra Brasil & 12 & 1 \\
Tudo Bem 1 & 6 & 3 \\
Tudo Bem 2 & 4 & 4 \\
Total: 12 & Total: 62 & Total: 34 \\
\hline
\end{tabular}

Fonte: Coelho de Souza (2014, p. 29)

No que diz respeito à presença de tarefas para a abordagem das canções, a Tabela 3 apresenta as seções dos livros nos quais as canções são apresentadas. Verifica-se que, com exceção das canções pertencentes à seção Intervalo, praticamente nenhuma das canções incluídas em seções cujos títulos expressam ideias associadas à descontração e lazer (como Recreio, Música e Sons da Terra) são acompanhadas por tarefas. Nesses livros, a audição da canção parece estar associada somente a um momento de descontração em sala de aula. Por outro lado, verifica-se que nas demais seções - Atividades, Leitura Suplementar, Exercício e as seções $A, B$ e $D$ das séries Avenida Brasil e Novo Avenida Brasil -, todas as canções estão vinculadas a tarefas, as quais passo a analisar a seguir. 
Tabela 3 - Seções em que há a presença de canções nos LDs analisados

\begin{tabular}{|c|c|c|c|}
\hline Coleção & Seções & $\begin{array}{c}\mathbf{N}^{\mathbf{o}} \\
\text { de } \\
\text { canções } \\
\end{array}$ & $\begin{array}{c}\mathbf{N}^{0} \text { de } \\
\text { canções } \\
\text { com tarefas }\end{array}$ \\
\hline $\begin{array}{l}\text { Aprendendo Português } \\
\text { Brasileiro }\end{array}$ & $\begin{array}{l}\text { Atividades (Música } \\
\text { Popular Brasileira) }\end{array}$ & 4 & 4 \\
\hline $\begin{array}{l}\text { Aprendendo Português } \\
\text { Brasileiro }\end{array}$ & Recreio & 1 & 0 \\
\hline $\begin{array}{l}\text { Aprendendo Português } \\
\text { Brasileiro }\end{array}$ & $\begin{array}{c}\text { Leitura } \\
\text { Suplementar }\end{array}$ & 1 & 1 \\
\hline Avenida Brasil 1 & D1, D2 & 2 & 2 \\
\hline Avenida Brasil 2 & $\mathrm{~A} 3, \mathrm{~B} 1, \mathrm{D} 1, \mathrm{D} 2$ & 7 & 7 \\
\hline Bem-Vindo & Exercício & 3 & 1 \\
\hline Fala Brasil & Música & 11 & 1 \\
\hline Falar...Ler... Escrever... & Música & 1 & 0 \\
\hline Falar... Ler... Escrever... & Intervalo & 5 & 5 \\
\hline Novo Avenida Brasil 1 & D1 & 1 & 1 \\
\hline Novo Avenida Brasil 2 & D2 & 1 & 1 \\
\hline Novo Avenida Brasil 3 & $\mathrm{D}, \mathrm{A}, \mathrm{D} 1$ & 3 & 3 \\
\hline Terra Brasil & Sons da Terra & 12 & 1 \\
\hline Tudo Bem 1 & Música $^{9}$ & 3 & 0 \\
\hline Tudo Bem 1 & Exercício & 3 & 3 \\
\hline Tudo Bem 2 & Exercício & 4 & 4 \\
\hline
\end{tabular}

Fonte: Coelho de Souza (2014, p. 29)

\section{Análise das tarefas}

Uma análise mais detalhada das 34 tarefas $^{10}$ encontradas permite verificar que as questões que as compõem podem ser

\footnotetext{
${ }^{9}$ Embora não tenha título, esta seção apresenta a letra da canção em um box separado com um desenho de um teclas de piano acima.

Horizontes de Linguística Aplicada, ano 16, n. 1, 2017 
A canção brasileira nos livros didáticos de português...

classificadas em quatro grandes categorias, sendo que duas englobam a grande maioria das ocorrências: perguntas de leitura e perguntas de compreensão oral. Além dessas duas categorias, há algumas tarefas que contêm questões que enfocam algum tipo de produção escrita ou algum aspecto textual específico (como acentuação), enquanto há outras que levam em conta, mesmo que de modo incipiente, usos sociais e reações à canção enquanto gênero do discurso. Passo agora a discorrer sobre os quatro tipos de tarefas $^{11}$ encontradas nos LDs analisados, descrevendo seus objetivos e trazendo exemplos.

\subsection{Leitura}

Das 34 tarefas analisadas, 21 englobam perguntas que enfocam a leitura da letra da canção com diferentes objetivos. A fim de melhor compreendê-los, lanço mão da tipologia de perguntas de compreensão proposta por Marcuschi (2001), que as divide em nove categorias ${ }^{12}$ : a cor do cavalo branco de Napoleão (resposta incluída na própria pergunta), cópias (transcrição de informações no texto), objetivas (identificação de informações explícitas no texto), inferenciais (relação de conhecimentos textuais com outros tipos de conhecimento), globais (envolvem o texto como um todo), subjetivas (relacionadas superficialmente ao texto, envolvem a opinião do aluno), vale-tudo (admitem qualquer resposta), impossíveis (só podem ser respondidas com conhecimentos externos ao texto) e metalinguísticas (relativas a questões formais do texto). $\mathrm{O}$ autor aponta que algumas perguntas

${ }^{10}$ Para fins quantitativos, as tarefas sobre as canções presentes tanto na coleção Avenida Brasil 1 e 2 quanto na série Novo Avenida Brasil 1, 2 e 3 foram contadas como distintas, mesmo sendo iguais ou praticamente iguais.

${ }^{11}$ Lembro que uma mesma tarefa pode incluir questões que se encaixam em diferentes categorias, sendo assim computadas como ocorrências distintas. Logo, o somatório do número de tarefas incluídas nas quatro categorias ultrapassa as 34 tarefas analisadas.

${ }^{12}$ Marcuschi (2001) explica que a tipologia por ele proposta "não é a única nem a mais correta, mas serve para indicar alguns aspectos interessantes da prática escolar quanto ao fenômeno da compreensão" (MARCUSCHI, 2001, p. 51). Para os propósitos desta análise, a tipologia foi produtiva, fornecendo critérios relevantes para a análise das tarefas de leitura.

Horizontes de Linguística Aplicada, ano 16, n. 1, 2017 
podem ser classificadas em mais de uma classe, sendo assim consideradas híbridas ou mistas.

Além das nove categorias apresentadas por Marcuschi (2001), para melhor entender os objetivos das 50 perguntas e subperguntas de leitura encontradas nas tarefas analisadas, tornou-se necessário elaborar mais duas categorias: as lexicais, que se referem a questões de vocabulário (como o reconhecimento de sinônimos), e as interpretativas, que dizem respeito à compreensão de versos da canção.

Como podemos ver na Figura 1, o maior número de questões encontradas foi o de perguntas objetivas (12 ocorrências), seguido pelas globais (11 ocorrências), híbridas/mistas (seis ocorrências), subjetivas/vale-tudo ${ }^{13}$ (cinco ocorrências), lexicais (cinco ocorrências), interpretativas (quatro ocorrências), cópias (três ocorrências), inferenciais (três ocorrências) e metalinguísticas (uma ocorrência). Não houve ocorrências de perguntas do tipo a cor do cavalo branco de Napoleão nem do tipo impossíveis.

Figura 1 - Tipos de perguntas de leitura presentes nos LDs

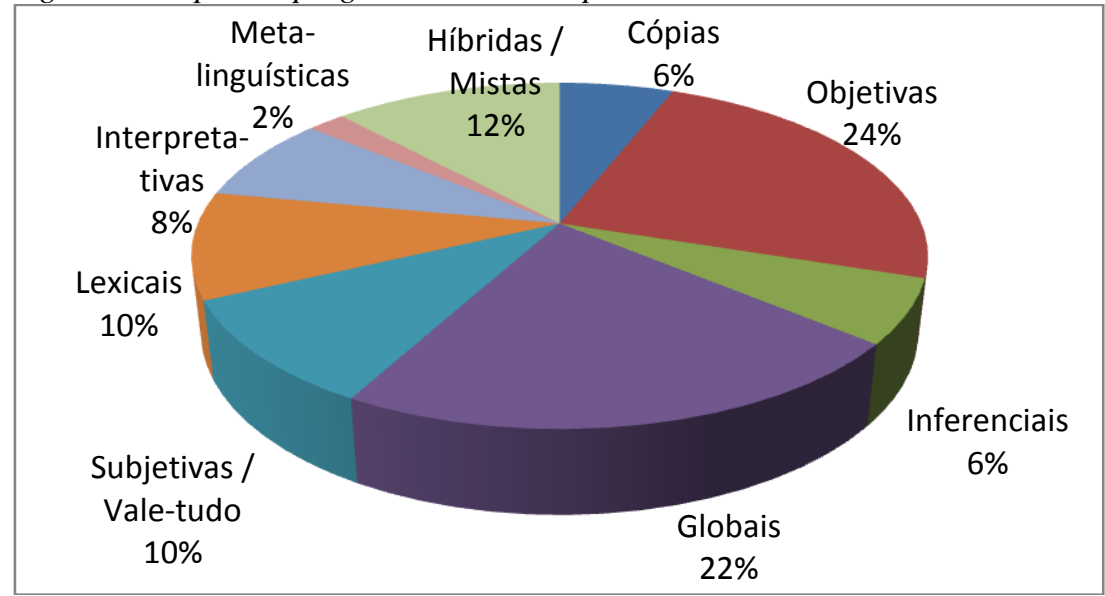

Fonte: Coelho de Souza (2014, p. 31)

${ }^{13}$ Não foi realizada uma distinção entre as perguntas subjetivas e as perguntas vale-tudo uma vez que a linha que as separa é muito tênue e não se tornou relevante diferenciá-las.

Horizontes de Linguística Aplicada, ano 16, n. 1, 2017 
A canção brasileira nos livros didáticos de português...

Das perguntas objetivas, categoria com maior representatividade nos LDs de PLA investigados, as 12 questões solicitam que o aluno leia o texto com o objetivo de: marcar as opções corretas, assinalar se uma informação está certa ou errada com relação ao texto, identificar informações específicas e relacionar colunas com informações presentes na letra da canção. Podemos encontrar exemplos de perguntas referentes à identificação de informações no estudo da canção $A$ Banda, apresentadas abaixo, na qual, com base nos versos "O homem sério que contava dinheiro parou / $\mathrm{O}$ faroleiro que contava vantagens parou / A namorada que contava as estrelas parou / Para ver, ouvir e dar passagem", as perguntas do grupo 1 e 2 apenas pressupõem respostas como "O homem sério contava dinheiro" e "O homem sério parou para ver, ouvir, e dar passagem”.

\section{Figura 2 - Trecho da tarefa sobre A Banda}

2. Ouça a música novamente e responda.

1. Como estava a cidade antes de à banda passar? Considere a população.

o homem sério

a namorada

a moça triste

a rosa triste

a lua cheia

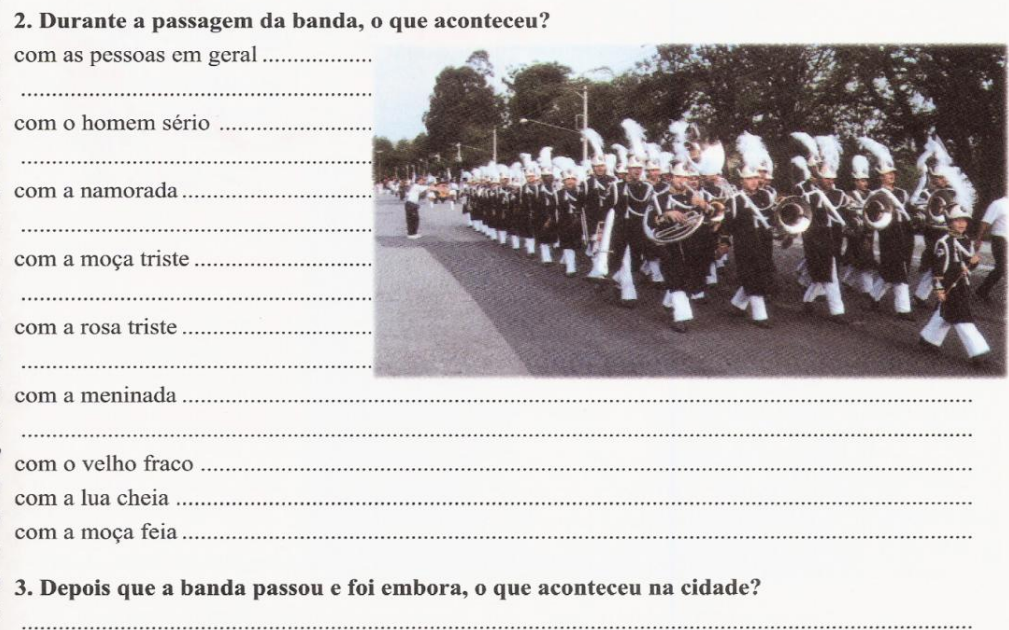

Fonte: Falar... Ler... Escrever... Português (LIMA; IUNES, 1999, p. 207)

Horizontes de Linguística Aplicada, ano 16, n. 1, 2017 
Por outro lado, as 11 perguntas globais encontradas envolvem ações como escolher palavras que podem ser mais associadas ao conteúdo da letra, criar um título para a canção, relacionar as semelhanças e diferenças entre as personagens, fazer uma descrição física e psicológica das personagens, dizer do que trata a letra, compreender se o ponto de vista do compositor é otimista ou pessimista, compreender o contexto pessoal e social da personagem e desenhar a paisagem retratada na canção, como podemos ver na figura 3:

Figura 3 - Trecho da tarefa sobre O Barquinho

4. Desenhe a paisagem que a canção descreve.

\author{
Dia de luz \\ festa de sol \\ e o barquinho a deslizar \\ no macio azul do mar \\ tudo é verão \\ o amor se faz \\ num barquinho pelo mar \\ que desliza sem parar. \\ Sem intenção nossa canção \\ vai saindo desse mar \\ e o sol beija o barco e luz \\ dias são azuis \\ Volta do mar \\ desmaia o sol \\ e o barquinho a deslizar \\ e a vontade de cantar \\ Céu tão azul \\ ilhas do sul \\ e o barquinho é um coração \\ deslizando na canção \\ Tudo isso é paz \\ tudo isso traz \\ uma calma de verão e então \\ o barquinho vai \\ a tardinha cai \\ o barquinho vai
}

Fonte: Avenida Brasil 1 (LIMA et al., 1991, p. 118)

No que diz respeito às seis perguntas híbridas/mistas, elas foram categorizadas desse modo por abrangerem, simultaneamente, interpretação e cópia (localizar no texto paráfrases de um trecho fornecido) e cópia e metalinguística (destacar ou retirar do texto verbos em tempos verbais específicos). Um exemplo deste subtipo 
A canção brasileira nos livros didáticos de português...

pode ser visto abaixo nas questões c) e d) sobre a canção Sinal Fechado:

Figura 4 - Trecho da tarefa sobre Sinal Fechado

Retirar do texto:

a) Todas as expressões de saudação:

b) Todas as expressões de cortesia:

c) Todos os verbos no presente do indicativo:

d) Todos os verbos no imperativo:

Fonte: Aprendendo Português do Brasil (LAROCA; BARA; CUNHA, 2003, p. 39)

Com relação às cinco questões subjetivas/vale-tudo, uma convida o aluno a refletir se, assim como o compositor, gostaria de ter uma casa no campo e por quê. Já as outras quatro solicitam que o aluno imagine como são determinados locais e personagens, como no estudo de $O$ trem das onze. Embora os alunos possam basear-se nas informações fornecidas pelo eu lírico sobre a razão de ter que deixar a mulher amada, como diz o próprio enunciado da questão $\mathrm{B}$, é necessário que o aluno use sua criatividade para descrever o eu lírico, sua mãe e Jaçanã.

Figura 5 - Trecho da tarefa sobre Trem das Onze 


\section{B.Use sua imaginação.}

1. Descreva o rapaz

2. Como é sua mãe?

3. Que idéia você faz do bairro em que ele mora? Justifique.

\section{Explique.}

1. Só amanhã de manhã.

2. Tenho minha casa pra olhar.

Fonte: Falar... Ler... Escrever Português (LIMA; IUNES, 1999, p. 161)

Além das questões subjetivas/vale tudo, as perguntas lexicais também tiveram cinco ocorrências. Como vimos, estas dizem respeito a ações como o reconhecimento de sinônimos e a inferência do significado de palavras e expressões idiomáticas, como nas questões 6 e 7 presentes na tarefa sobre Conversa de Botequim:

Figura 6-Trecho da tarefa sobre Conversa de Botequim

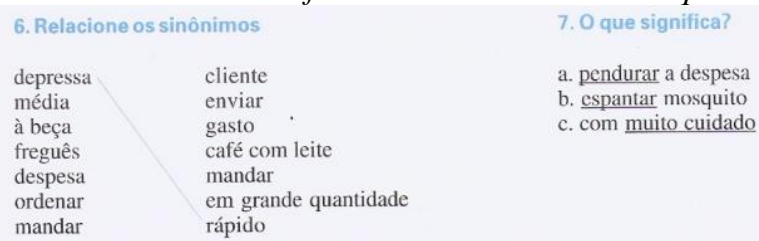

Fonte: Avenida Brasil 1 (LIMA et al., 1991, p. 101)

As quatro perguntas classificadas como interpretativas, como também já vimos, envolvem a compreensão do significado de versos da canção (com ou sem a sugestão de opções). Podemos encontrar um exemplo desse tipo de pergunta na questão $\mathrm{C}$ sobre $O$ trem das onze, apresentada anteriormente na Figura 5.

Duas categorias tiveram três ocorrências cada: as perguntas de cópias, que envolvem a identificação e/ou retirada de expressões da letra da canção, e as inferenciais, que nas tarefas analisadas propõem que o aluno reflita sobre a relação entre o refrão de uma canção e a compreensão global de outra canção e estabeleça relações entre uma Horizontes de Linguística Aplicada, ano 16, n. 1, 2017 
A canção brasileira nos livros didáticos de português...

afirmação sobre a canção e a compreensão global da letra. Exemplos de questões pertencentes a essas duas categorias podem ser encontrados no estudo da canção Asa Branca, na Figura 7: enquanto a primeira pergunta requer que o aluno encontre palavras como "ardendo", "braseiro", "fornalha", presentes na letra da canção enfocada, as duas questões seguintes requerem que o aluno compreenda a razão de a asa branca, pássaro que vive no nordeste brasileiro, ter fugido do sertão, a relação entre a seca e a decisão do eu lírico de emigrar, e o contraste entre a tristeza em ter que sair das suas terras e a esperança de que o verde dos olhos de Rosinha, sua amada, espalhe-se novamente pela plantação.

\section{Figura 7 - Trecho da tarefa sobre Asa Branca \\ Responda. \\ 1. Aponte, na letra, as palavras ligadas à idéia de sol e de falta de chuva. \\ 2. "Até mesmo a asa branca / Bateu asas do sertão". Este fato é significativo. Por quê? \\ 3. Apesar de muito triste, o sertanejo está otimista. Explique.}

Fonte: Falar... Ler... Escrever... Português (LIMA; IUNES, 1999, p. 248)

Finalmente, no que tange à pergunta de metalinguagem presente nas tarefas investigadas, solicita-se que o aluno pondere sobre o uso do pretérito perfeito e do pretérito imperfeito com base nos exemplos presentes na canção Valsinha em versos como "Olhou-a de um jeito muito mais quente / Do que sempre costumava olhar", incluída na obra Fala Brasil (FONTÃO; COUDRY, 1995, p. 123, grifos dos autores).

\subsection{Compreensão oral}

Foram encontradas 17 questões envolvendo a prática da compreensão oral, sendo que nove solicitam que o aluno ouça a canção para preencher lacunas. O preenchimento de lacunas nessas tarefas é proposto de três maneiras diferentes: sem a apresentação prévia das palavras a serem utilizadas, com a apresentação e com a sugestão de opções de palavras com sonoridade parecida. Embora as duas últimas formas de trabalhar com lacunas já se distingam um pouco da abordagem tradicional da canção em aulas de línguas, conforme 
afirmamos em Coelho de Souza (2009, p. 18), "ouvir a canção somente com esse objetivo reduz a canção a um instrumento de avaliação em uma perspectiva muito restrita de compreensão oral, focada apenas na identificação de algumas palavras do texto".

Podemos ver abaixo um trecho da tarefa sobre Conversa de Botequim, na qual o aluno é convidado a ouvir a canção para selecionar qual palavra preenche a lacuna em cada verso.

Figura 8 - Trecho da tarefa sobre Conversa de Botequim

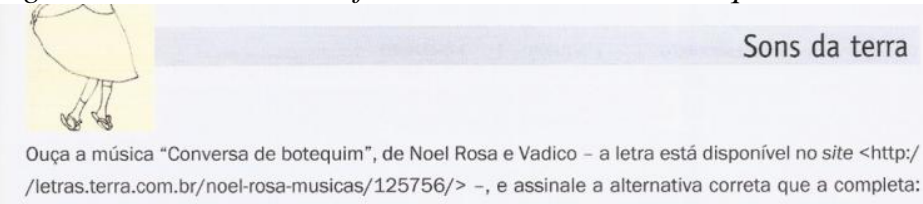

Conversa de botequim

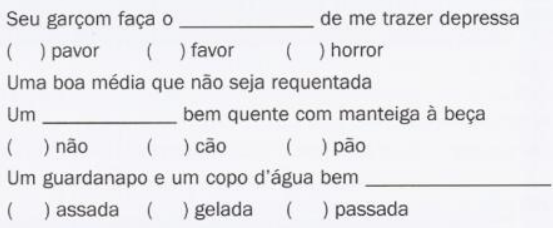

Fonte: Terra Brasil (DELL' ISOLA; ALMEIDA, 2008, p. 123)

As tarefas também propõem a audição da canção tanto com objetivos de compreensão específica, tais como ordenar versos, encontrar palavras que faltam, corrigir palavras que foram trocadas de posição e anotar palavras-chave, quanto de compreensão global, como dizer sobre o que trata a letra, associar o conteúdo da letra a imagens e desenhar uma figura que ilustre o que foi compreendido. Podemos observar a seguir uma tarefa com dois desses objetivos no estudo da canção Uma partida de futebol, a qual também inclui uma pergunta que envolve a compreensão escrita da letra: 
A canção brasileira nos livros didáticos de português...

Figura 9 - Trecho da tarefa sobre Uma Partida de Futebol

EXERCÍCIO 7. DESENHANDO A CANÇÃO

Enquanto você ouve a música, desenhe tudo - que entender sobre a canção. Escreva também algumas palavras que poderão ajudá-lo a contar uma das estrofes aos colegas. Cada grupo de três ou quatro alunos ficará responsável por apenas uma estrofe, entretanto todos poderão desenhar a música inteira.

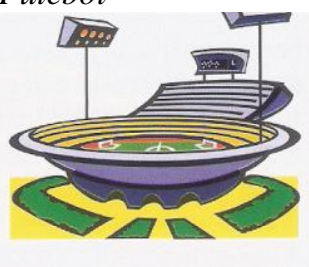

Qual é o nome da canção?

Fonte: Tudo Bem 2 (PONCE; BURIM; FIORISSI, 2010, p. 86)

\subsection{Produção escrita}

Apenas cinco das 34 tarefas analisadas incluem questões que envolvem algum tipo de produção escrita ou relacionada a elementos textuais. Enquanto há duas questões que envolvem a acentuação de palavras ou a criação de novos versos para a canção, as outras três relacionam-se à reprodução da letra em um registro mais formal, como na tarefa abaixo:

Figura 10 - Trecho da tarefa sobre As Mariposa

\section{Ouvindo música no fim de semana: MPB}

1. Ouça o texto

- Adoro ficar em casa ouvindo rádio. A gente ouve música, notícias ... Ontem ouvi um cantor diferente: Adoniran Barbosa! Você conhece?

- Conheço e gosto muito dele. Ele é muito original. Superinteressante. E fala tudo errado.

2. Ouça a música de Adoniran Barbosa e diga do que trata a letra.

3. Ouça novamente a música e reproduza a letra, verso por verso, em linguagem padrão culto (coloquial).

Fonte: Novo Avenida Brasil 3 (LIMA et al., 2010, p. 55)

Verificam-se nesta tarefa algumas imprecisões que podem levar o aluno a uma compreensão equivocada sobre a relação entre o compositor e o eu lírico de uma canção e sobre a questão da variação linguística. Nota-se que quando uma das personagens do diálogo Horizontes de Linguística Aplicada, ano 16, n. 1, 2017 
afirma que conhece Adoniran Barbosa, ela diz que o considera muito original e que "fala tudo errado". Primeiramente, se entendemos que as diferentes variantes linguísticas que se apresentam nas letras de canções brasileiras são uma expressão do plurilinguismo $^{14}$ (CARETTA, 2011), o registro de linguagem utilizado pelo compositor na canção As Mariposa pode ser visto como uma representação de uma determinada variante, no caso bastante estigmatizada, e não decorre que o cantor seja falante dessa variante, mesmo porque o eu lírico não é o compositor. Além disso, ao não problematizar a relação entre a linguagem utilizada na canção e a classe socioeconômica dos personagens nela retratados, percebe-se que "a variação, quando reconhecida, é simplesmente sinônimo de erro" (BAGNO; RANGEL, 2005, p. 72). Além disso, há uma imprecisão terminológica por parte dos autores no uso do termo "linguagem padrão culto (coloquial)", uma vez que não fica claro à qual registro de linguagem os autores estão referindo-se: à norma culta, à norma-padrão ou ao registro coloquial.

\subsection{Aspectos da canção enquanto gênero do discurso}

Por fim, seis tarefas relacionam a canção a práticas sociais ou chamam a atenção para algum aspecto intrínseco ao gênero, como o seu caráter expressivo e o seu gênero musical. Com relação àquelas, as tarefas convidam o aluno para ouvir a canção para cantar junto ou para posicionar-se em relação à canção ouvida a partir do seu gosto pessoal. No que diz respeito às perguntas que envolvem elementos da canção enquanto gênero formado por letra e música, elas envolvem selecionar fotos que melhor retratem o tema da letra e a sensação produzida pela canção ou ler a definição de um determinado gênero musical para imaginar como é a canção, como na tarefa sobre a canção Coimbra, apresentada na figura 11 .

\section{Resultados da análise}

${ }^{14}$ Segundo Bakhtin (2002) toda língua possui uma heterogeneidade intrínseca revelada pelos dialetos sociais, que se relacionam não apenas às classes sociais, mas também aos gêneros, às gerações, às profissões, etc.

Horizontes de Linguística Aplicada, ano 16, n. 1, 2017 
A canção brasileira nos livros didáticos de português...

A análise dos dados aqui apresentados evidencia um número considerável de ocorrências de letras de canções no corpus analisado, visto estarem presentes em $75 \%$ das 16 obras pesquisadas. Com relação às coleções que não incluem textos desse gênero, embora sejam recentes, tendo sido publicadas entre 2003 e 2008, no que concerne à presença da canção nessas obras, elas parecem destoar da tendência verificada por Castro (2006, p. 21) de que a maior parte dos LDs de PLA produzidos a partir de 2001 "apresenta avanços na utilização de textos autênticos de gêneros variados - sejam eles verbais ou não verbais". Além disso, esta alta representatividade pode ser vista como um reconhecimento por parte dos autores desses LDs do papel da canção na cultura nacional e da sua importância como produto cultural brasileiro de ampla referência no exterior (NAPOLITANO, 2005).

Figura 11 - Trecho da tarefa sobre Coimbra

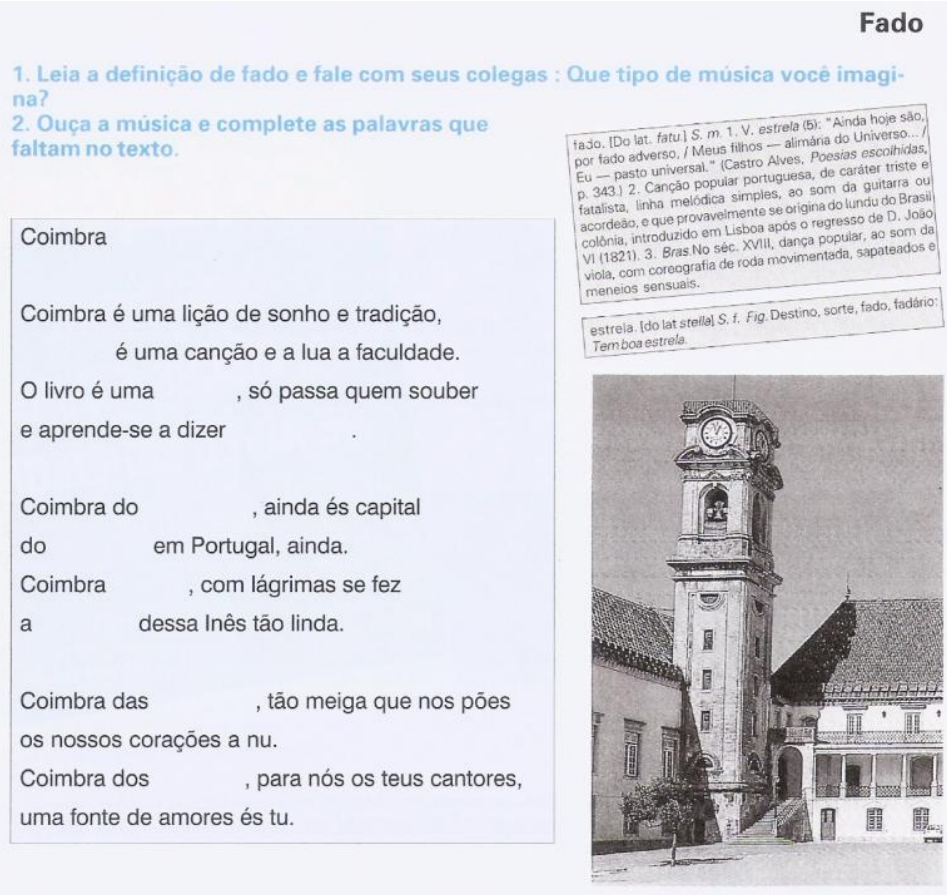

Horizontes de Linguística Aplicada, ano 16, n. 1, 2017 
Fonte: Avenida Brasil 2 (LIMA et al., 2005, p. 15)

No que tange ao estudo das canções, verificou-se que pouco mais da metade $(54,84 \%)$ das 62 canções presentes nessas coleções são efetivamente acompanhadas por tarefas para o seu estudo, sendo a sua grande maioria de leitura e compreensão oral. Embora isso aponte inicialmente para uma visão, mesmo que ainda que um tanto limitada, do potencial pedagógico da canção ${ }^{15}$, verificou-se que as tarefas referentes ao seu estudo presentes nas obras analisadas, quando existentes, quase sempre tem como objetivo a leitura e a compreensão oral da letra da canção desvinculada de seus usos sociais e de elementos da música, sua outra linguagem constitutiva, para a construção de sentidos.

Com relação às perguntas de leitura, uma análise mais pormenorizada nos mostra que pouco mais de um terço $(36 \%)$ das 50 questões $^{16}$ requer uma compreensão mais ampla ou de trechos específicos ou do texto como um todo por parte dos alunos, além da capacidade de construir relações intratextuais e intertextuais. Embora esses números destoem positivamente dos resultados encontrados por Marcuschi $(2001)^{17}$, ainda assim, 15 perguntas $^{18}$ (30\%) envolvem apenas a identificação de informações no texto. Nesse sentido, quase um terço das perguntas colocam os alunos apenas no papel de decodificadores dos textos, não os estimulando a usar, participar e analisar as canções em estudo (LUKE; FREEBODY, 1990 apud GIBBONS, 2000).

Por outro lado, no que concerne à prática da compreensão oral, embora pouco mais da metade das tarefas de compreensão oral

${ }^{15}$ Ver Gobbi (2001), Coelho de Souza (2009) e Barbosa (2011) para exemplos de práticas pedagógicas com base em canções que buscam desenvolver as quatro habilidades.

${ }^{16}$ Foram contabilizadas as perguntas globais, inferenciais e interpretativas.

$17 \mathrm{O}$ autor analisou 2360 questões presentes em 25 livros didáticos de português como língua materna, das quais $70 \%$ envolvem apenas a localização de informações no texto (53\% objetivas, $16 \%$ cópias e $1 \%$ cavalo branco).

${ }^{18}$ Foram contabilizadas as perguntas objetivas e as cópias. 
A canção brasileira nos livros didáticos de português...

presentes nos LDs investigados ainda tenha entre seus objetivos o preenchimento de lacunas, percebe-se que os autores desses livros estão lançando mão de outras propostas de abordagem para a canção, inclusive envolvendo uma compreensão mais geral da canção. Acreditamos que o uso de lacunas não seja um problema em si, mas que não é a única forma de propiciar a prática dessa habilidade ao ouvir uma canção. Por isso, ao selecionar essa dinâmica é importante que o professor reflita sobre "por que razão e com que objetivo retira palavras da letra, se para praticar rimas, sentidos possíveis do texto, alguma classe gramatical específica ou a percepção de alguns sons específicos, tendo sempre em vista o grau de compreensibilidade da palavra ao ouvir a canção" (COELHO DE SOUZA, 2009, p. 18).

Além das 21 tarefas que incluem perguntas de leitura e das 17 que envolvem a compreensão oral da letra da canção, apenas seis tarefas incluem questões que procuram enfocar aspectos da canção enquanto gênero discursivo e, dentre elas, três resumem-se a convidar o aluno para cantar junto. Essas tarefas, aliadas às canções presentes nas seções intituladas Recreio, Música e Sons da Terra, nas quais não há a presença de tarefas para o seu estudo, parecem reforçar o caráter de lazer da sua audição em detrimento de uma abordagem que focalize elementos presentes na letra e na música para a construção de sentidos da canção em estudo. Não há dúvida de que ouvir canções para relaxar, descontrair e cantar junto sejam usos sociais bastante comuns fora de sala de aula e, por essa razão, sejam objetivos válidos para desenvolver a fruição de um repertório de canções na língua em foco e ampliar a participação em um dos usos que comumente fazemos desse gênero discursivo: ouvir canções pelo prazer que nos proporcionam. Contudo, acreditamos que, embora ter a fruição como objetivo pedagógico para o uso de canções em aulas de PLA faça parte de um entendimento da canção enquanto gênero do discurso, esse não deveria ser o único objetivo e, caso seja, deveria ser proposto conjuntamente com orientações para sua apreciação. Ademais, esses resultados parecem corroborar a afirmação de Ginet (1995 apud BARBOSA, 2001) de que a canção é ainda geralmente utilizada para "trabalhar um item gramatical específico, quebrar o ritmo, dar uma aula 'diferente', 'recompensar' os alunos por terem assimilado uma unidade $\mathrm{X}$ ou $\mathrm{Y}$, complementar um tema, 'recuperar' um conteúdo que foi mal 
assimilado e/ou 'rechear' uma unidade com um passatempo", sem um tratamento pedagógico mais aprofundado.

Por fim, no que diz respeito à concepção de canção subjacente aos LDs em questão, assim como os resultados das análises de LDs realizadas por Gada (2005) e por Lacerda (2011) ${ }^{19}$, as tarefas analisadas não fazem menção a elementos da linguagem musical, trazendo uma abordagem somente da letra da canção em estudo, sem nenhuma questão enfocando a articulação das duas linguagens para a construção de sentidos da canção. Da mesma maneira, assim como nos resultados encontrados pelas autoras, não há explicitação alguma de elementos relacionados ao contexto de produção, circulação e/ou recepção das canções analisadas, o que poderia fornecer aos alunos insumos para uma compreensão mais responsiva da canção em estudo.

Assim, por ignorar a linguagem musical e as práticas sociais mediadas pela canção em estudo para construção de sentidos da mesma, podemos inferir que a grande maioria dos autores de livros didáticos ainda não vê a canção como um gênero discursivo multimodal, mas apenas como um gênero apenas verbal, ou seja, como letra de música ${ }^{20}$. Por essas razões, concluímos que o tratamento dado à canção nas coleções analisadas não dá conta de aspectos inerentes ao gênero, tais como os usos sociais a ela associados, a linguagem musical e sua articulação com a verbal para a produção de sentidos.

Acreditamos que os resultados da análise aqui apresentada apontam para a necessidade de refletirmos sobre uma abordagem da canção em aulas de (P)LA que busque promover o seu estudo de forma mais holística, ou seja, que leve em conta a linguagem musical e suas possíveis articulações com a verbal para a construção dos sentidos da canção, e que procure discutir questões relacionadas à canção enquanto gênero discursivo, como a interlocução projetada por ela, seus

${ }^{19}$ Em suas pesquisas de mestrado, Gada (2005) e Lacerda (2011) analisaram coleções de livros didáticos de português como língua materna a fim de observar o tratamento dado às canções por parte dos autores das obras.

${ }^{20}$ Apesar de toda canção ser composta por letra e música, entendo que letra de canção (ou coloquialmente letra de música) e canção são gêneros discursivos distintos, uma vez que este é um gênero oral formado por letra e música enquanto aquele é um gênero escrito e formado apenas pela linguagem verbal, e que, consequentemente, circulam em suportes distintos.

Horizontes de Linguística Aplicada, ano 16, n. 1, 2017 
A canção brasileira nos livros didáticos de português...

contextos de produção, circulação e recepção, e seus usos e funções sociais. Dessa forma, estaremos proporcionando uma compreensão mais ampla da canção enquanto gênero discursivo, permitindo que os alunos possam participar de modo mais efetivo e autoral nas práticas sociais por ela mediadas e nos discursos que se organizam a partir dela.

\section{Referências}

APPLE, Michael. W.; CHRISTIAN-SMITH, Linda. K. The politics of the textbook. In: . The politics of the textbook. New York, NY: Routledge, 1991.

BAGNO, Marcos; RANGEL, Egon de O. Tarefas da educação linguística no Brasil. Revista Brasileira de Linguística Aplicada, v. 5, n. 1, p. 63-81, 2005.

BAKHTIN, Mikhail. Discurso no romance. In: - Questões de literatura e de estética: a teoria do romance. São Paulo: HUCITEC, 2002. p. 71-210.

BARBOSA, Lúcia. M. A. Apontamentos sobre a utilização da música popular brasileira na aula de português para estrangeiros. In: IV CONGRESSO DA SOCIEDADE INTERNACIONAL DE PORTUGUÊS - LÍNGUA ESTRANGEIRA, 2001, Rio de Janeiro.

Anais do IV Congresso da Sociedade Internacional de Português Língua Estrangeira. Rio de Janeiro - RJ: PUC-Rio, 2001. p. 1-5.

BARBOSA, Nicole C. Língua e canção: proposta de tarefa com canção no ensino de português como língua adicional. 2011. Monografia (Graduação em Letras) - Instituto de Letras, Porto Alegre: Universidade Federal do Rio Grande do Sul, 2011.

BIZON, Ana. C. C.; FONTÃO, Elizabeth. Estação Brasil: português para estrangeiros. Campinas: Editora Átomo, 2005. 
CARETTA, Álvaro C. A. Relações discursivas entre a canção popular e os gêneros primários da comunicação. Estudos Linguísticos, v. 36, n. 3, p. 158-165, 2007.

A canção e a cidade: estudo dialógico discursivo da canção brasileira e seu papel na constituição do imaginário da cidade de São Paulo na primeira metade do século XX. Tese (Doutorado em Semiótica e Linguística Geral) - Faculdade de Filosofia, Letras e Ciências Humanas, Universidade de São Paulo, São Paulo, 2011.

CARVALHO, Simone C. Políticas de promoção internacional da língua portuguesa: ações na América Latina. Trabalhos em Linguística Aplicada, v. 51, n. 2, p. 459-484, 2012.

CASTRO, Pedrina B de. Produção escrita: encontros e desencontros entre os livros didáticos de português do Brasil para estrangeiros e o exame Celpe-Bras. Dissertação (Mestrado em Linguística Aplicada) Instituto de Letras, Universidade Federal Fluminense, Niterói, 2006.

COELHO DE SOUZA, José P. Canção brasileira: proposta de material didático para um curso de português como língua adicional. 2009. Monografia (Graduação em Letras), Instituto de Letras, Universidade Federal do Rio Grande do Sul, 2009.

A canção na ótica dos gêneros discursivos: uma constelação de gêneros. Cadernos do IL,n. 40, p. 123-133, 2010.

- Letramento literomusical: práticas sociais mediadas por canções. Revista Matraga, v. 22, n.36, p. 175-197, 2015.

COSTA, Nélson B. A letras e a letra: o gênero canção na mídia literária. In: DIONÍSIO, Ângela P.; MACHADO, Anna Rachel; BEZERRA, Maria Auxiliadora. (Org.). Gêneros textuais e ensino. Rio de Janeiro: Lucerna, 2002. p. 107-121.

DELL' ISOLA, Regina L. P; ALMEIDA, Maria José A. Terra Brasil: Curso de Língua e Cultura. Belo Horizonte: Editora UFMG, 2008. 
A canção brasileira nos livros didáticos de português...

DINIZ, Leandro R. A. Mercado de línguas: a instrumentalização brasileira do português como língua estrangeira. Dissertação (Mestrado em Linguística) - Instituto de Estudos da Linguagem, Universidade Estadual de Campinas, Campinas, 2008.

FERNANDES, Glaucia R. R.; FERREIRA, Telma L. S. B.; RAMOS, Vera L. Muito prazer. São Paulo: DISAL, 2008.

FONTÃO; Elizabeth; COUDRY, Pierre. Fala Brasil: português para estrangeiros. Campinas: Pontes, 1995.

GADA, Ana Lúcia C. A canção no livro didático de língua portuguesa. Dissertação (Mestrado em Letras) - Centro de Ciências Humanas, Letras e Artes, Universidade Estadual de Maringá, Maringá, 2005.

GIBBONS, Pauline. Scaffolding language, scaffolding learning: teaching second language learners in the midstream classroom. Portsmouth, NH: Heinemann, 2002.

GOBBI, Denise. A música como estratégia de aprendizagem no ensino de língua inglesa. Dissertação (Mestrado em Letras) - Instituto de Letras, Universidade de Caxias do Sul e Universidade Federal do Rio Grande do Sul, Porto Alegre, 2001.

JÚDICE, N. \& ALMEIDA, P.M.C. de (2006). Revisitando um livro didático de português para estrangeiros dos anos 40. Português em debate, Niterói, RJ.

LACERDA, Viviane N. O ensino do gênero canção em aulas de língua portuguesa: um estudo de educação linguística. Dissertação (Mestrado em Letras) - Centro de Comunicação e Letras, Universidade Presbiteriana Mackenzie, São Paulo, 2011. 
LAROCA, Maria N. C.; BARA, Nadine; CUNHA, Sonia M. Aprendendo português do Brasil: um curso para estrangeiros. Campinas: Pontes, 2003.

LIMA, Emma E. O. F et al. Avenida Brasil 1: curso básico de português para estrangeiros. São Paulo: Editora Pedagógica e Universitária, 1991.

et al. Avenida Brasil 2: curso básico de português para estrangeiros. São Paulo: Editora Pedagógica e Universitária, 1995.

et al. Novo Avenida Brasil 1: curso básico de português para estrangeiros. São Paulo: EPU, 2008.

et al. Novo Avenida Brasil 2: curso básico de português para estrangeiros. São Paulo: EPU, 2009.

et al. Novo Avenida Brasil 3: curso básico de português para estrangeiros. São Paulo: EPU, 2010.

.; IUNES, Samira A. Português via Brasil: um curso avançado para estrangeiros. São Paulo: EPU, 2005.

.; __ Falar... ler... escrever... português: um curso para estrangeiros. São Paulo: EPU, 1999.

.; ___ _ _ LEITE, Marina R. Diálogo Brasil: curso intensivo de português para estrangeiros. São Paulo: Editora Pedagógica e Universitária, 2003.

MARCUSCHI, Luiz A. Compreensão de texto: algumas reflexões. In: DIONISIO, Ângela; BEZERRA, Maria Auxiliadora. (Orgs.) O livro didático de português: múltiplos olhares. Rio de Janeiro, Lucerna, 2001. p. 46-59.

NAPOLITANO, M. História \& Música - história cultural da música popular. $3^{\text {a }}$ edição, Belo Horizonte: Autêntica, 2005. 
A canção brasileira nos livros didáticos de português...

PONCE, Maria H. O.; BURIM, Silvia R. B. A; FIORISSI, Susana. Tudo bem?: português para a nova geração - Volume 1. São Paulo: Special Book Services Livraria, 2000.

PONCE, Maria H. O.; BURIM, Silvia R. B. A; FIORISSI, Susana. Tudo bem?: português para a nova geração - Volume 2. São Paulo: Special Book Services Livraria, 2010.

; ; Bem vindo!: a língua portuguesa no mundo da comunicação. São Paulo: Special Book Services Livraria, 2009.

RIO GRANDE DO SUL. Secretaria de Educação do Estado, Departamento Pedagógico. Referenciais curriculares do Estado do Rio Grande do Sul: linguagens, códigos e suas tecnologias. V. I. Porto Alegre: SE/DP, 2009.

SCHLATTER, Margarete; GARCEZ, Pedro M. Línguas adicionais na escola: aprendizagens colaborativas em inglês. Erechim: Edelbra, 2012.

TROUCHE, Lygia M. G.; JÚDICE, Norimar P. M. Tópicos em português como língua estrangeira. Cadernos do CNLF (CiFEFil), v. 9, n. $5, \quad 2005.2$ Disponível em: <http://www.filologia.org.br/ixcnlf/5/16.htm>. Acesso em: 30 nov. 2016.

Recebido em: 01/03/2017

Aceito em: 28/06/2017

Title: The place and role of Brazilian songs in Portuguese as an additional language textbooks 